\title{
Relevance of Removal of Limbic Structures in Surgery for Temporal Lobe Epilepsy
}

\author{
André Olivier
}

\begin{abstract}
We have briefly reviewed the experimental and clinical evidence for the importance of the amygdala and hippocampal formation in temporal lobe epilepsy. More specifically, we have analyzed our own experience in patients with temporal lobe epilepsy investigated with intracerebral stereotaxic electrodes and operated by various modalities of resection. Our results, in agreement with previous experimental and clinical work, provide further evidence for an overwhelming predominance of limbic participation in temporal lobe epilepsy. As a result, more and more selective procedures are being carried out involving the mesial structures. However, this shift has been slow and progressive because of the proven value of cortico-amygdalo-hippocampectomy which provides excellent results on seizure tendency with low morbidity.
\end{abstract}

\begin{abstract}
RÉSUMÉ: Pertinence de l'ablation des structures limbiques dans le traitement chirurgical de l'épilepsie temporale. Nous avons revu les données expérimentales et cliniques démontrant l'importance de l'amygdale et de l'hippocampe dans l'épilepsie temporale. Nous avons, en particulier, revu notre propre expérience chez les patients avec épilepsie temporale investigués avec des électrodes stéréotaxiques intracérébrales et subséquemment opérés selon diverses modalités de résection. Nos résultats, en accord avec les travaux expérimentaux et cliniques antérieurs, démontrent sans équivoque une prédominance très nette des structures limbiques dans l'épilepsie temporale. En conséquence, nous procédons de plus en plus à des procédures sélectives impliquant les structures mésio-basales (amygdale et hippocampe). Ce changement d'attitude cependant se produit de façon lente et progressive du fait que la cortico-amygdalo-hippocampectomie s'est depuis longtemps avérée une procédure qui donne des résultats excellents sur la tendance épileptique, avec une faible morbidité.
\end{abstract}

Can. J. Neurol. Sci. 1991; 18: 628-635

Among the many factors which influence outcome in the surgery of epilepsy, the extent and modalities of resections are probably the most neglected and poorly studied. More specifically the importance of removing both the amygdala and hippocampus in the surgery of temporal lobe epilepsy remains unclear in spite of the large number of temporal lobe operations performed at the Montreal Neurological Institute (MNI) ${ }^{1-4}$ and the numerous series reported in the literature.5.6 The development of procedures permitting a more selective removal of these structures has activated the debate.

\section{Historical Review}

The question of modalities and extent of temporal removals was already being assessed in the mid $1950 \mathrm{~s}^{7-9} \mathrm{~A}$ failure rate of the order of $21 \%$ in 51 cases of temporal excisions operated between 1939 and 1949 was attributed by Penfield to a too limited resection of the temporal lobe especially of its internal structures. ${ }^{9}$ Based on a subsequent series of 81 patients operated over a 3 year period Penfield introduced the systematic removal of the uncus and hippocampus.9,3
By the mid 50's a series of experimental and clinical studies had already demonstrated the low seizure threshold of the mesial temporal structures and their importance in the manifestations of epilepsy. ${ }^{10-17}$ Based on this evidence Niemeyer in 1958 developed a selective transcortical transventricular removal of the amygdala and hippocampus. ${ }^{17}$

At the MNI the extent and modalities for resection of mesiotemporal structures have varied to a certain extent according to the surgeon involved. Penfield in his 1939-1949 series of 51 cases attributed many of the failures to incomplete temporal lobe removal especially of its mesial structures and by $1954^{9}$ he was removing both the uncus and hippocampus. Feindel, after having produced evidence for a very important role played the amygdala in the human temporal epilepsy12,13 has recommended its removal but not that of the hippocampus. Rasmussen's attitude has been to proceed with a resection of the anterior hippocampus when active hippocampal spiking is detected following the cortical and amygdala removal. 1 This conservative approach was in keeping with the risks to memory function of hippocampal removals emphasized by Scoville and Milner. ${ }^{18}$

The purpose of this presentation is to further delineate the role played by the mesio-temporal structures in temporal epilep- 
sy and to assess the importance of their selective removal in the light of our surgical material and to give a brief review of the functional anatomy of the region.

\section{Recordings with Stereotactic Depth and Surface Electrodes}

In our series of patients studied with stereotactically placed intracerebral electrodes for bitemporal epilepsy (Figure 1) the vast majority of seizures were found to originate in the limbic structures. 19,20 These seizures arose either in the hippocampus or amygdala but more frequently in the hippocampus, with very quick spread from one structure to the other. Seizures of strict neocortical onset were rare; however, rapid spread of the discharge recruitment of the neocortex was the rule. Although these patients were evaluated because of the presence of bilateral interictal epileptiform activity they demonstrated a unilateral onset in the vast majority (77\%) of cases. They were later submitted to an anterior cortical resection with amygdalo-hippocampectomy. The analysis of 48 patients with a minimal follow-up of 2 years showed that $40 \%$ were greatly improved, $46 \%$ had a worthwhile improvement and $15 \%$ were not significantly improved. ${ }^{21}$

\section{Stimulation with Intracerebral Electrodes}

Stimulation studies also done with stereotactic intracerebral electrodes in both the neocortical and limbic structures of the temporal lobe (Figure 1) have shown that many of the characteristic clinical features of temporal lobe epilepsy, including the patient's habitual aura can be reproduced by stimulation of the amygdala and hippocampus but rarely from the neocortical contacts. ${ }^{22}$ When electrical stimulation gave rise to seizures, they were almost exclusively of limbic onset, slightly more often from the amygdala than from the hippocampus. ${ }^{20}$ These findings are also in keeping with our peroperative stimulation results under local anaesthesia where the patient's habitual aura, psychic phenomena, automatisms and after discharges are

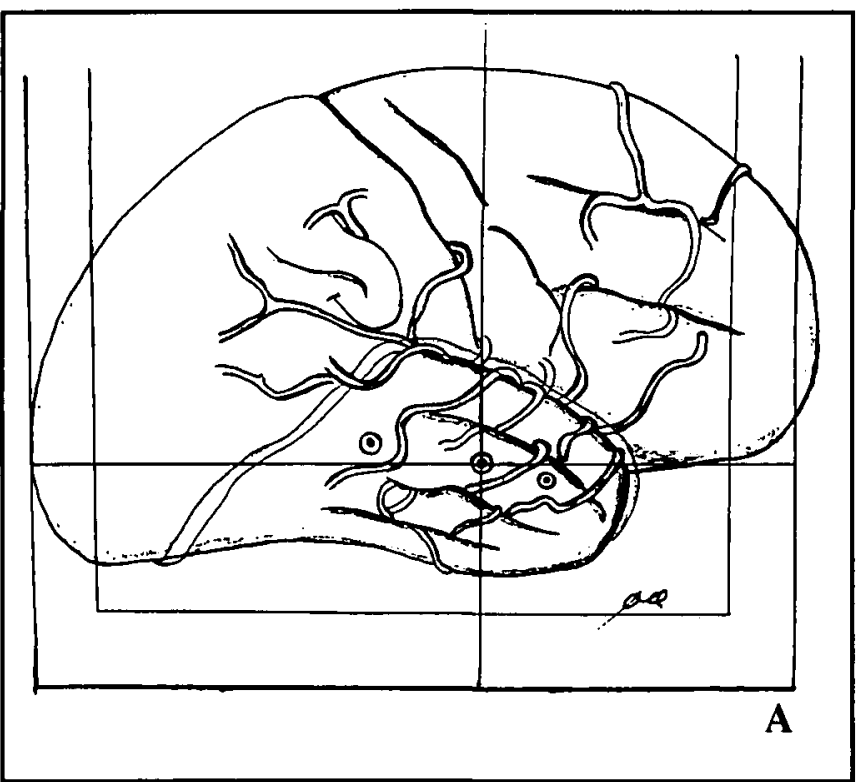

obtained almost exclusively from recording through the deepest contacts (unpublished observations). They are also in keeping with the original work of Feindel et al. ${ }^{12,13}$ on the stimulation of the amygdala region in the human.

\section{Effects of Hippocampal Resection or Sparing}

Additional evidence for the importance of the hippocampus in epilepsy was derived from comparison of cases where the hippocampus was resected with cases where it was left alone in a series of anterior temporal resections. ${ }^{4}$ By "anterior resection" we mean a removal of the anterior 4 to $5 \mathrm{~cm}$ of the anterior temporal cortex (Figure 2). The hippocampal resection in these patients amounted to the anterior $1.5-2 \mathrm{~cm}$ of the hippocampus proper and the corresponding parahippocampal gyrus (Figures $2,3)$. The effect of such removal or sparing has been considered for both the right and the left sided operations. To analyze the results on seizure tendency we have subdivided patients into three groups according to a classification inspired by Crandall. ${ }^{23}$ Group A represents patients who are seizure free or have a maximum of three seizures per year following surgery. Group B includes patients whose attacks have been reduced by at least $50 \%$. Groups A and B constitute the "success" group. Group C comprises those patients who were not improved or only slightly improved by surgery. Out of 116 patients operated on the right side with an average follow-up of 2.5 years ( 1 to 5 years) 20 patients or $17.2 \%$ had no hippocampal resection and 96 or

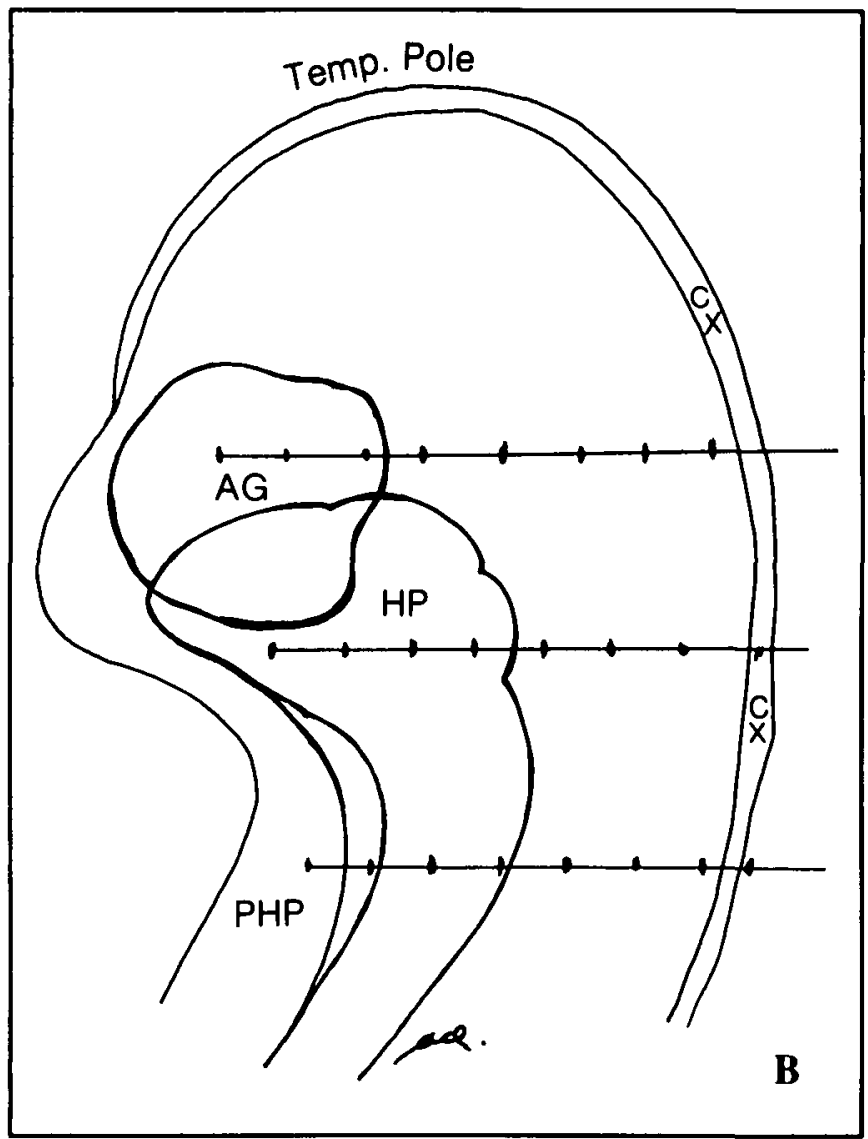

Figure $1-(A)$ Diagram to illustrate the placement of stereotactic depth electrodes, using angiography. (B) Diagram in transverse plane showing placement of stereotactic depth electrodes for recording and stimulation of temporal limbic and neocortical structures. AG = amygdala, $H P=$ hippocampus, $P H P=$ parahippocampus, $C X=$ neocortex . 


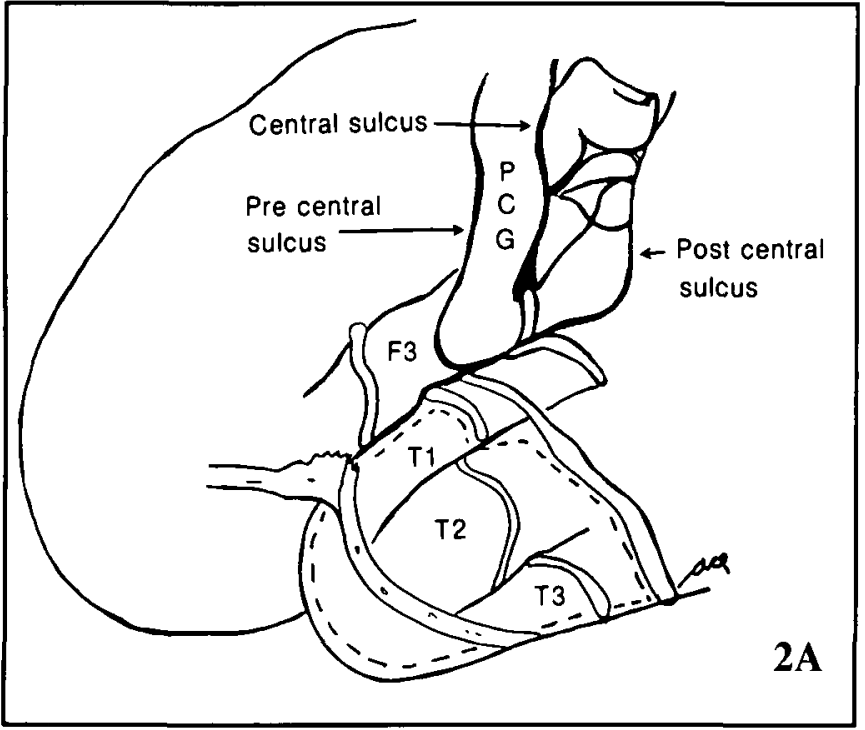

Figure $2-(\boldsymbol{A})$ Diagram showing identification of central area, surface topography of temporal lobe and habitual extent of neocortical removal in dominant hemisphere. $P C G=$ precentral gyrus. Note: site of somato-topical responses for tongue, lips and thumb in lower post-central gyrus. (B) Diagram in transverse plane showing the habitual extent of cortical and limbic removal in dominant hemisphere.

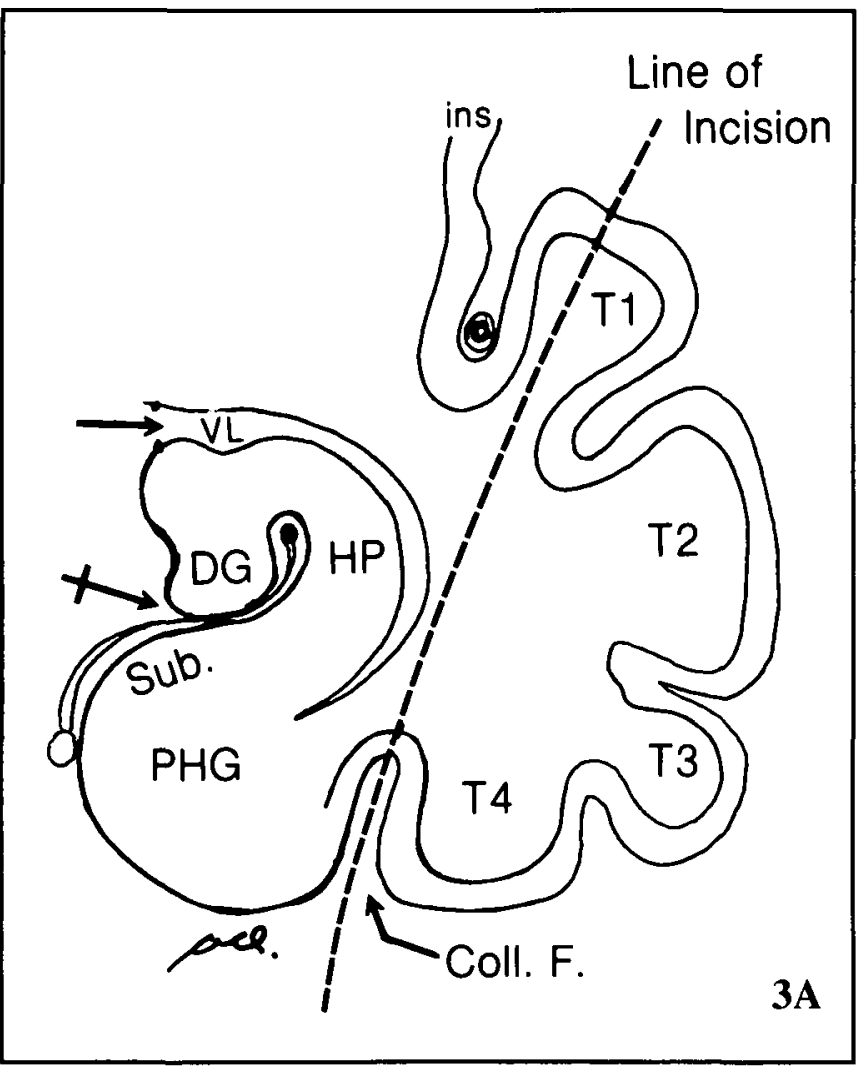

Figure $3-($ A) Neocortical resection. Coronal diagram showing line of excision for "en bloc" neocortical removal (T1 to collateral fissure). (B) Hippocampectomy by transventricular subependymal-subpial aspiration with ultrasonic dissector (CUSA). Note: position of hippocampal sulcus and artery used as a landmark (crossed arrow). SUB = subiculum, $P H G=$ parahippocampal gyrus.
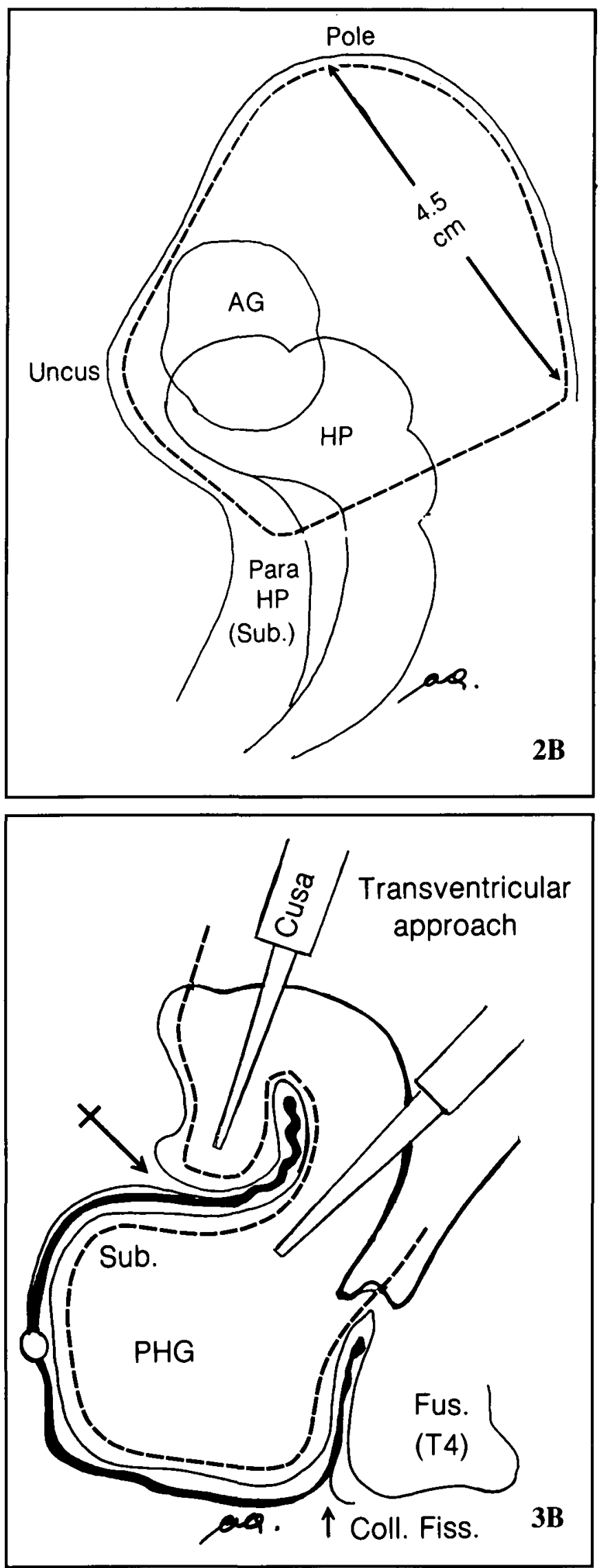
$82.8 \%$ had this structure removed. The right sided group of patients with hippocampal removal has done significantly better with an overall success rate of $88.5 \%$. In patients where the hippocampus was not removed, the success rate decreases to $70 \%$ (60\% in Group A, $10 \%$ in Group B). Nevertheless, $60 \%$ of the patients with hippocampal sparing will eventually be in Group A compared to $67 \%$ for those who had the more complete removal.

Of 105 patients operated on the left side with an average follow-up of 3.1 years ( 1 to 10 years) 35 patients or $33.3 \%$ had no resection of the hippocampal formation and 70 patients or $66.6 \%$ had this structure removed. Findings are similar to those with right sided resections. Patients with hippocampal removal have done significantly better (overall success of $84.3 \%$ ), than patients with hippocampal sparing who have done poorly with a success rate of $60 \%$ ( $34 \%$ in Group A, $26 \%$ in Group B). Following hippocampal removal $48.5 \%$ of the patients were within Group A compared to $34 \%$ in patients with hippocampal sparing. Thus in the author's series, the failure rate was found to be higher in cases where the hippocampus has been left alone. This is in keeping with the work of Penfield ${ }^{9}$ and Van Buren. ${ }^{5}$ These results also indicate that a significant proportion of
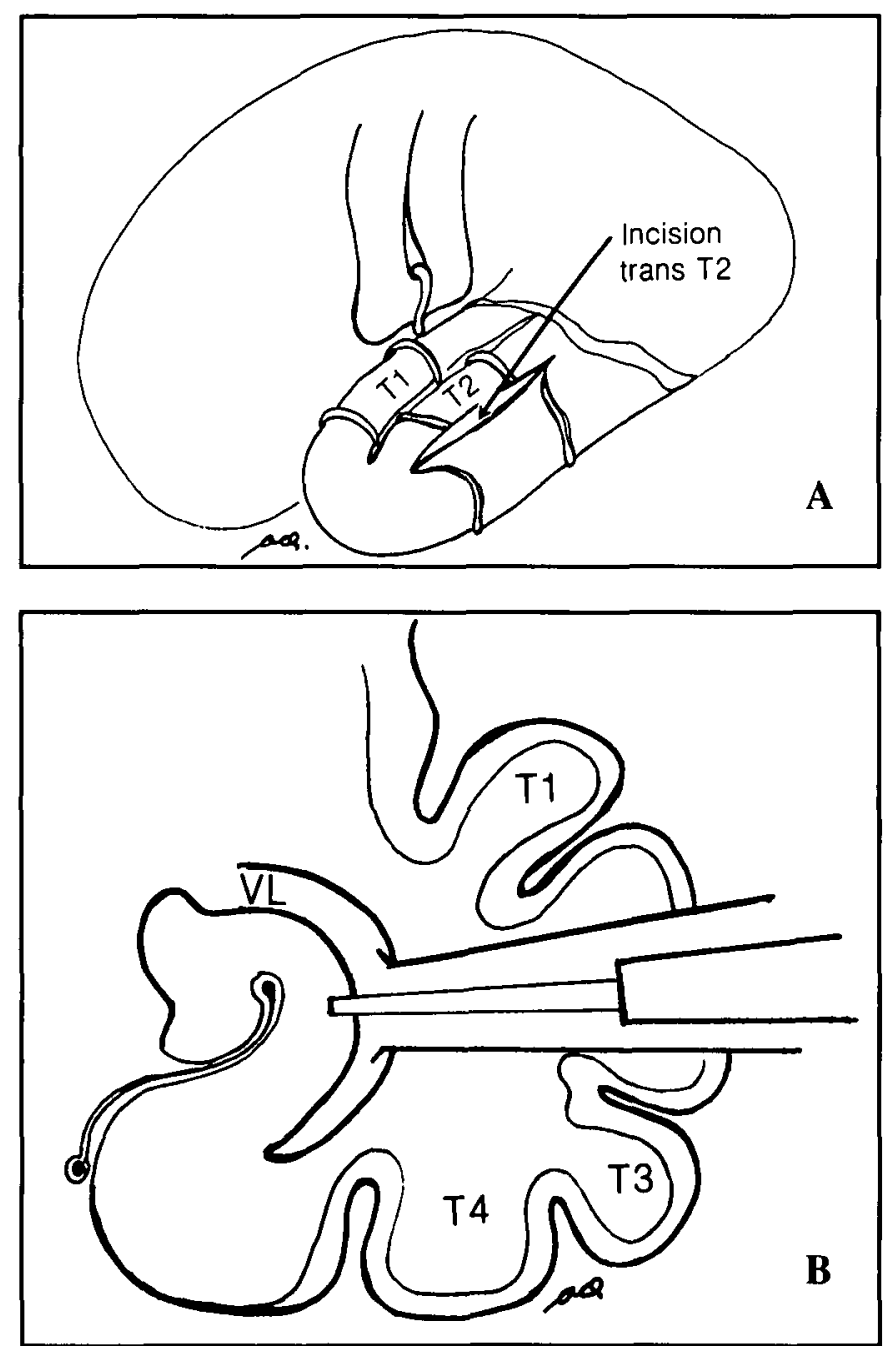

patients can have a successful outcome with cortico-amygdalectomy with hippocampectomy.

\section{Effect of Secondary Hippocampectomy (Reoperations)}

Further insight into the role of the hippocampal formation in the triggering and persistence of seizures has been obtained by the analysis of results of reoperations where only or predominantly the hippocampal formation was resected.24,25 Penfield and Jasper ${ }^{9}$ had already observed in 1954 that in some patients with poor results, reoperation had shown an epileptic focus in the hippocampus and that "complete hippocampal removal has sometimes converted failures into what promises to become success".

In 20 patients who were considered failures and had no resection or a very limited anterior resection of the hippocampus, a second operation was carried out which consisted essentially of removing the hippocampal formation through the previous surgical cavity. Following reoperation 6 patients or $30 \%$ became seizure free, 3 patients $(15 \%)$ had a marked reduction in seizure number and 7 patients (35\%) had a worthwhile improvement. Four patients (20\%) had no significant improvement.

In most instances the decision to leave the hippocampus in place was based on neuropsychological findings and on the intracarotid Amytal test. These data suggest an important role for the hippocampal formation in the persistence of some seizures and suggest that this structure should be removed whenever possible at the time of surgery. ${ }^{24,25}$

\section{Effect of Selective Amygdalo-Hippocampal Resection}

The work of Niemeyer 17.26 and more recently of Wieser et al.27-29 show that a high percentage of patients operated by selective amygdalo-hippocampal resection can obtain seizure

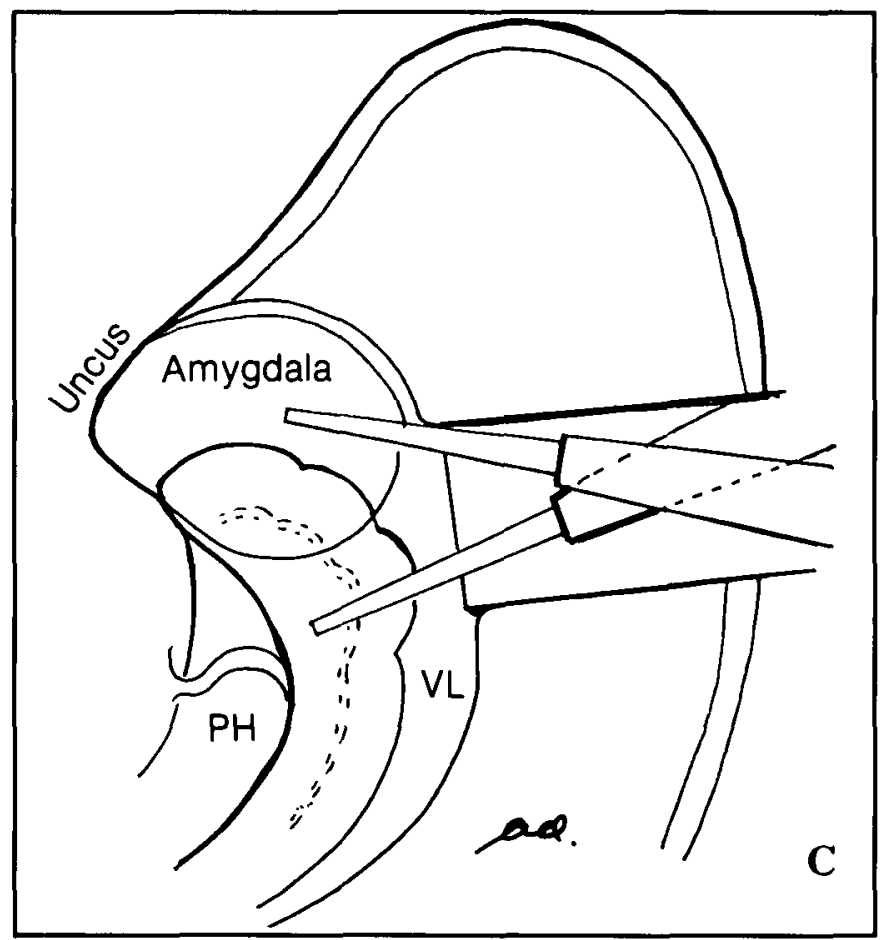

Figure $4-(\boldsymbol{A})$ Diagram showing transcortical approach to the temporal horn. (B) Showing transcortical (T2) approach to the ventricle and hippocampus. Coronal view. (C) Transcortical, transventricular approach to the hippocampus and amygdala. Transverse view. 
control. Our preliminary results with selective transcortical amygdala resection of amygdalo-hippocampectomy are also encouraging. More often the procedure has consisted of removal of amygdala, uncus and anterior hippocampus through a transcortical T2 approach (Figure 4). Full evaluation in more than 20 patients with selective removal is not yet available. When the first 9 cases with minimal follow-up from 6 months to 3 years were evaluated 5 patients were in Group A, 3 patients in Group B and 1 patient in Group C.

\section{Functional Anatomy of the Amygdala and Hippocampus}

Most of the discussions and conclusions about the extent and modalities of surgery are only meaningful as long as the anatomical boundaries and connections of the structures involved are well defined. Accordingly we will briefly review some important aspects of the anatomy of the mesio-limbic structures.

Surgically, we define the amygdala region as a mass of grey matter occupying the anterior wall of the temporal horn and blending mesially into the anterior part of the uncus. Its anterior border corresponds grossly to the plane of the horizontal segment of the middle cerebral artery. Its dorsal limit is also poorly defined and corresponds to a plane running from the endorhinal sulcus to the base of the insular sulcus. The hippocampus proper and the parahippocampus make up the hippocampal formation. These two structures are best identified surgically in reference to the uncal or hippocampal sulcus (Figure 3). Unless otherwise specified, hippocampectomy entails removal of the hippocampus proper and of the corresponding portion of the parahippocampal gyrus.

\section{Connections of the Amygdala (Figures 5, 6, 8)}

Until recently most connections of the amygdala were thought to be represented by the stria terminalis and the ventral amygdalofugal pathway. ${ }^{30}$ Recent immunohistochemical studies have shown a bewildering number of amygdala connections with the neocortex and subcortical structures. ${ }^{31}$ Direct inter-connection between the amygala and hippocampus, (Figures 5, 6, 8)

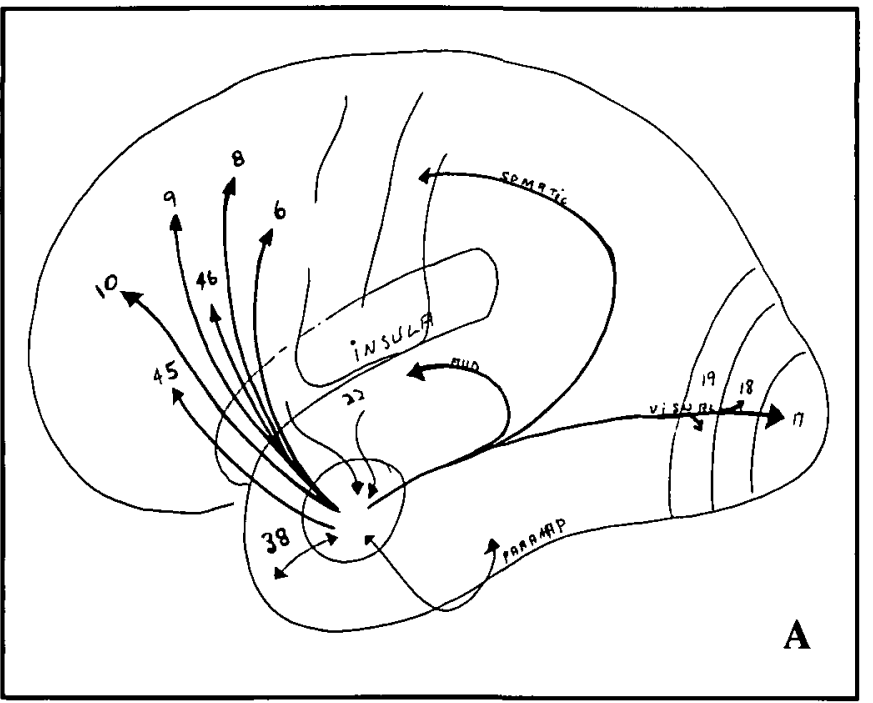

the temporal and frontal cortex (Figure 5) are now well documented. ${ }^{31}$ Most areas of the frontal lobe, but especially the orbito-frontal, cingular and lateral convexity have been shown to have many interconnections with the amygdala (Figure 5).

\section{Connections of the Hippocampal Formation (Figures 6, 7)}

Most of the incoming and outgoing bundles of fibers to and from the hippocampal formation interconnect with the parahippocampal and subicular area first and not directly with the hippocampus ${ }^{30,32,33}$ (Figure 5B). The basic connections of the hippocampal formation form an intrinsic trisynaptic pathway ${ }^{34}$ (Figures 6,7 ). The first synapse is formed by fibers of the perforant path arising in the parahippocampal gyrus and terminating in contact with the granule cells of the dentate gyrus. The second synapse is formed in the CA 3 segment between terminals of the granule cells (mossy fibers) and the pyramidal cell of the CA 3 segment of the hippocampus. The pyramidal cells of CA 3 send their fibers to cells of CA 2 and to those of the subiculum to form the third synapse. The subiculum can thus be considered as the area of reception and output of large and widespread neocortical fiber systems.

\section{Discussion}

Among the various factors which influence surgical outcome, the extent and modalities of resection are obviously of considerable importance. Echoing the original observations of Jackson, ${ }^{35}$ the numerous experimental studies of the 1950s such as those of Kaada, ${ }^{10}$ Vigouroux et al., ${ }^{11}$ Gastaut et al. ${ }^{14}$ and

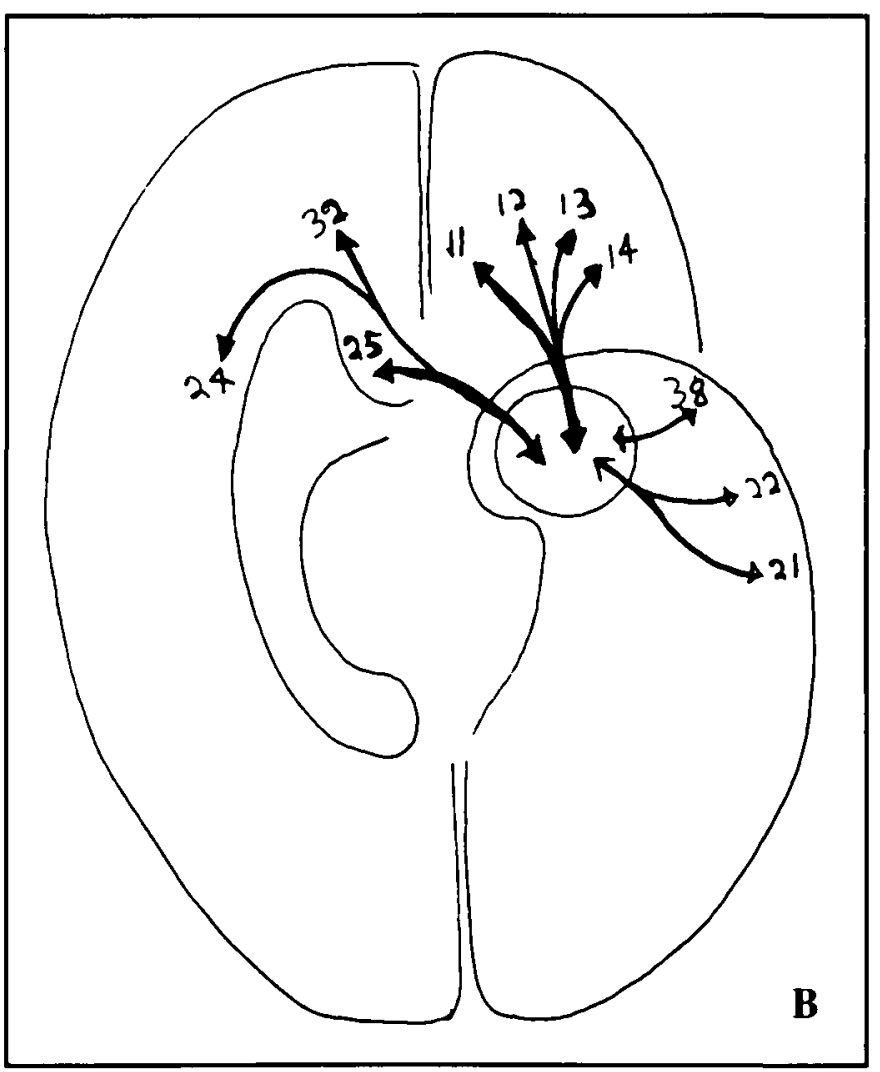

Figure 5 (see ref 31$)-(\boldsymbol{A})$ Connections of the amygdala with various cortical fields of the convexity. (B) Inter-connections of the amygdala with medio-orbital frontal and temporal cortical areas. 

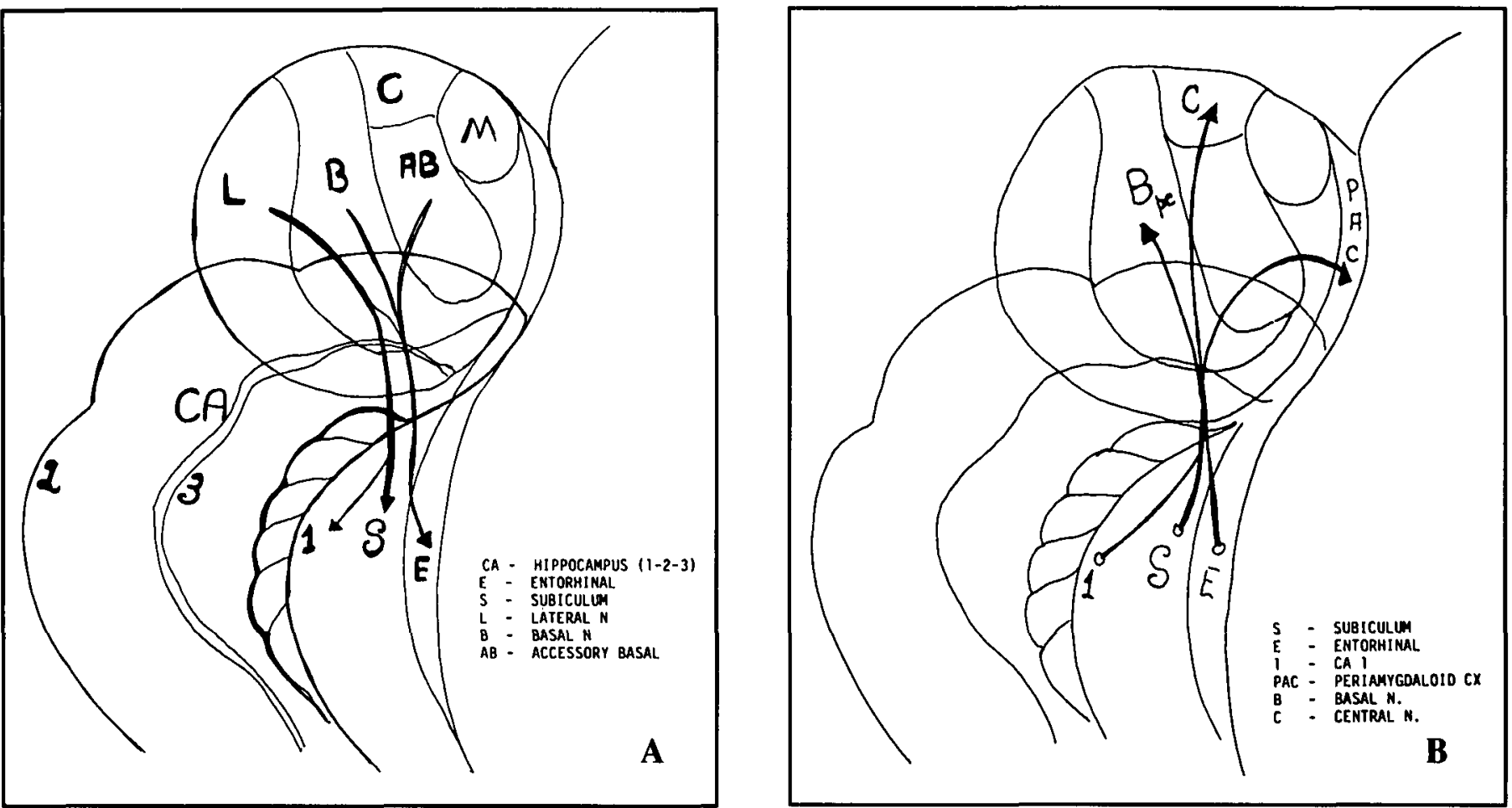

Figure 6 (see ref 31) - (A) Amygdalo-hippocampal connections. Fibers terminate predominantly in subicular and entorhinal areas. (B) Hippocampo-amygdalar connections. Fibers originate mainly from subicular and entorhinal areas.

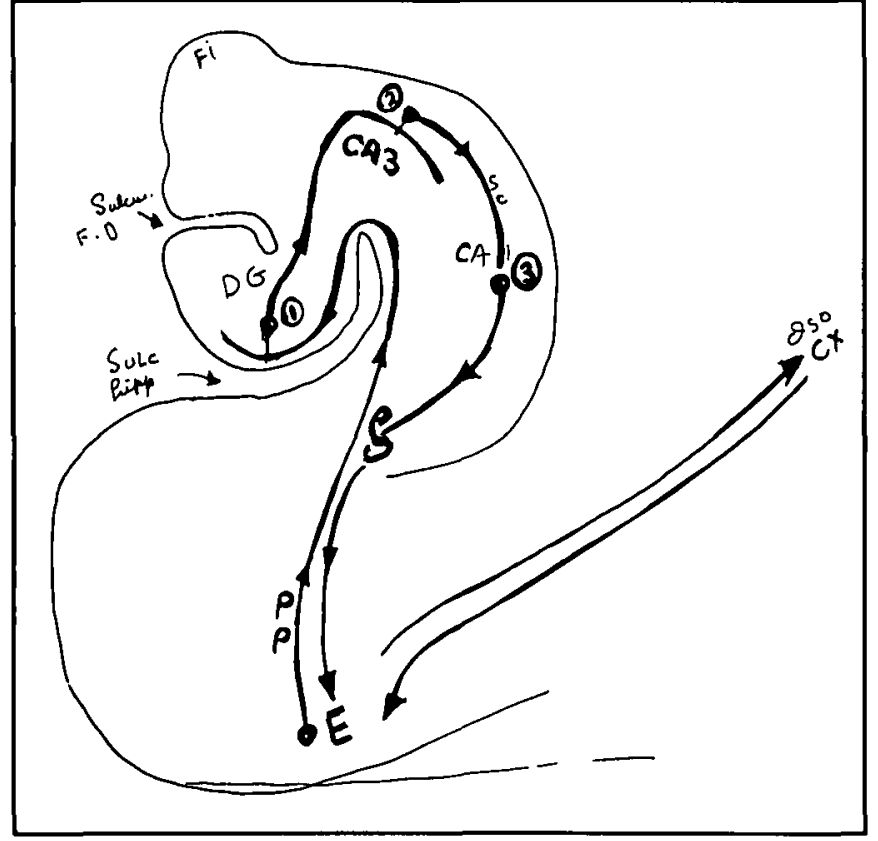

Figure 7 - Trisynaptic organization of hippocampal formation. $F l=$ fibria,$D G=$ dentate gyrus, $C A=$ hippocampal fields, $P P$ = perforant path.

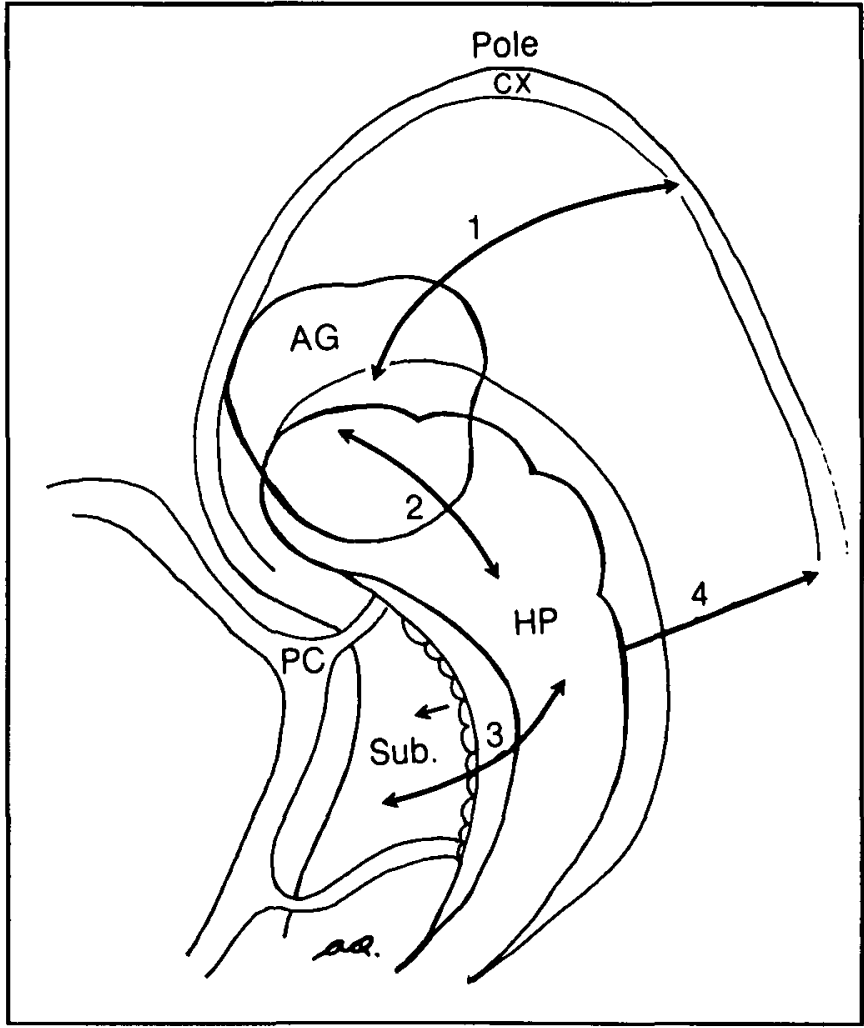

Figure 8 - Basic circuitry in temporo-mesial limbic structures. $C X=$ cortex,$A G=$ amygdala,$H P=$ hippocampus, $S U B=$ subiculum, $P C=$ posterior cerebral artery. $I=$ connections between amygdala and cortex, 2 = between amygdala and hip. pocampus, 3 = between parahippocampal gyrus and hippocampus, $4=$ between parahippocampus and cortex 
Green and Shimanoto, 15 and those carried out in humans by Feindel et al., ${ }^{12,13}$ Penfield and Jasper, ${ }^{9}$ Jasper $^{36-38}$ and Morris ${ }^{7}$ pointed to a very important role of the mesiobasal structures in temporal epilepsy both in animals and in humans. This evidence led Niemeyer to propose and carry out a procedure which he called transventricular amygdalo-hippocampectomy. ${ }^{17}$ It consisted of selective removal of the amygdala and hippocampus by a limited cortical incision through the second temporal gyrus. This procedure was a departure from the standard temporal lobectomy which was then in vogue. At the Tokyo International Meeting of Neurosurgery in 1973, Niemeyer further elaborated on the microsurgical technique of amygdalo-hippocampectomy. ${ }^{26}$ Later Yasargil, based on his extensive experience with operations through the base of the Sylvian fissure devised a transsylvian approach using a transcortical incision at the basis of the circular sulcus to reach the hippocampus and amygdala. Wieser and Yasargil have reported excellent results with seizure control using this approach. 27,28 Our experience with stereotactic recording and stimulation have shown an overwhelming predominance of epileptic discharges within the limbic structures in keeping with the work of Crandall et al..$^{39}$ and Halgren et al. ${ }^{40}$ although these authors have limited their studies to limbic electrodes only. Furthermore, our data based on reoperations in temporal epilepsy also indicate an important role played by the hippocampal formation in triggering temporal lobe seizures in the human. Surgical removal of these structures creates a widespread functional disconnection unsuspected until the recent demonstration by immunohistochemistry of amygdalal and hippocampal interconnectivity. These results have led us to carry out more restricted anterior temporal removal and more radical resection of the amygdala and hippocampus. Simultaneously we have carried out selective amygdalo-hippocampal removal by an approach similar to that of Niemeyer. The technique is essentially transcortical, transventricular, subependymal and subpial. The entire procedure can thus be carried out by the same endopial method which is used for the more standard cortical resection.

The vast majority of our cases of temporal procedures still consist of cortico-amygdalo-hippocampectomy. The anterior cortical removal provides direct unobstructed visualization of the amygdala and hippocampus without causing significant intellectual or cognitive deficit. ${ }^{41}$ In our opinion, cortico-amygdalo-hippocampectomy should remain the standard procedure. Meanwhile, we continue to evaluate the procedure of transcortical selective amygdalo-hippocampectomy. If seizure control obtained by the transcortical selective removal proves to be comparable or superior to that obtained with the more traditional approach, the selective resection may evolve into the procedure of choice in our institution.

\section{REFERENCES}

1. Rasmussen T. Surgical treatment of patients with complex partial seizures. In: Penry JK, Daly DD, eds. Advances in Neurology. Vol. 11, New York: Raven Press, NY. 1975; 415-449.

2. Penfield W, Flanigin H. Surgical therapy of temporal lobe seizures. Arch Neurol Psychiatry 1950; 64: 491-500.

3. Penfield W; Baldwin M. Temporal lobe seizures and the technics of subtotal temporal lobectomy. Ann Surg 1952; 136: 625-634.
4. Olivier A. Risk and benefit in the surgery of epilepsy: complications and positive results on seizure tendency and intellectual functions. In: Treatment of epilepsy. Acta Neurol Scand 1988; Supp 117, Vol. 78. 114-121.

5. Van Buren JM, Ajmone-Marsan C, Mutsuga N, et al. Surgery of temporal lobe epilepsy. In: Purpura DP, Penry JK, Walter RD, eds. Advances in Neurology. Vol. 8, Neurosurgical Management of the Epilepsies. New York: Raven Press 1975; 155-196.

6. Talairach J, Bancaud J, Szikla G, et al. Approche nouvelle de la neurochirurgie de l'épilepsie. Neurochirurgie 1974; 20, suppl 1.

7. Morris AA. Temporal lobectomy with removal of uncus, hippocampus and amygdala. Arch Neurol Psychiatry 1956; 76; 479496.

8. Ajmone-Marsan C, Baldwin M. Electrocorticography. In: Baldwin M, Bailey P, (eds). Temporal lobe epilepsy. Springfield (III): Charles Thomas, 1958; 368-395.

9. Penfield W, Jasper H. Epilepsy and the functional anatomy of the human brain. 1954. Little, Brown Boston.

10. Kaada BR. Somatomotor, autonomic and electrographic responses to electrical stimulation of "rhinencephalic" and other structures in primates, cat and dog: a study of responses from limbic, subcallosal, orbito-insular, pyriform and temporal cortex, hippocampus, fornix and amygdala. Acta Physiol Scand 1951; Suppl 83: 1-285.

11. Vigouroux R, Gastaut H, Badier M. Provocation des principales manifestations cliniques de l'épilepsie dite temporal par stimulation des structures rhinencéphaliques chez le chat non anaesthésié. Rev Neurol 1951; 85: 505-508.

12. Feindel W, Penfield W, Jasper H. Localization of epileptic discharge in temporal lobe automatism. Trans Neurol Assoc 1952; 14-17.

13. Feindel W, Penfield W. Localization of discharge in temporal lobe automatism. Arch Neurol Psychiatry 1954; 72: 605-630.

14. Gastaut HR, Vigouroux R, Naquet R. Lésions épileptogènes amygdalo-hippocampiques provoquées chez le chat par l'injection de "crème d'albumine". Rev Neurol 1952; 87: 607-609.

15. Green JD, Shimamoto T. Hippocampal seizures and their propagation. Arch Neurol Psychiatry 1953; 7: 687-702.

16. Cadilhac J. "Hippocampe et Epilepsie" Montpelier, Imprimerie Paul Dehan 1955; 205.

17. Niemeyer $P$. The transventricular amygdalohippocampectomy in temporal lobe epilepsy. In: Baldwin M, Bailey P, eds. Temporal Lobe Epilepsy. Springfield (III): Thomas. 1958; 461-482.

18. Scoville WB, Milner B. Loss of recent memory after bilateral hippocampal lesions. J Neurol Neurosurg Psychiatry 1957; 20: 1121.

19. Quesney LF, Olivier A, Andermann F, et al. EEG and clinical manifestations of frontal and temporal lobe seizures. Can J Neurol Sci 1987; 14: 252-253.

20. So N, Gloor P, Quesney LF, et al. Depth electrode investigations in patients with bitemporal epileptiform abnormalities. Ann Neurol $1989 ; 25: 423-431$.

21. So N, Olivier A, Andermann F, et al. Results of surgical treatment in patients with bitemporal epileptiform abnormalities. Ann Neurol 1989; 25: 432-439.

22. Gloor P, Olivier A, Quesney LF, et al. The role of the limbic system in experimental phenomena of temporal lobe epilepsy. Ann Neurol 1982; 12(2): 129-144.

23. Crandall P. Post-operative management and criteria for evaluation. In: Purpura DP, Penry JK, Walter RD, eds. Advances in Neurology: Vol 8, New York: Raven Press 1975; 265-279.

24. Tanaka T, Yonemasu Y, Olivier A, Andermann F. Clinical analysis of reoperation in cases of complex partial seizures. Neurol Surg (Japan) 1998; 17: 933-937.

25. Olivier A, Tanaka T, Andermann F. The significance of limbic structure removal in the surgery of temporal lobe epilepsy, based on reoperations. Proceedings of the Xth Meeting of the World Society for Stereotactic and Functional Neurosurgery Maebashi, Japan; 1989: 171.

26. Niemeyer P, Bello H. Amygdalo-hippocampectomy for temporal lobe epilepsy. Microsurgical Technique. Excerpta Medica 1973; 293: 20 (abstr no 48). 
27. Wieser HG, Yasargil MG. Die "Selective Amygohippokampektomie" als Chirurgische Behandlungsmethode du Mediobasallimbischen epilepsie. Neurochirurgia 1982; 25: 39-50.

28. Wieser HG. Selective amygdalohippocampectomy: Indications, investigative techniques and results. In: eds. Advances and technical standards in neurosurgery Vol. 13. New York: SpringlerWien 1986; 40-133.

29. Yasargil MG, Teddy PJ, Roth P. Selective amygdalo-hippocampectomy: operative anatomy and surgical technique. $I n$ : Symon $L$ et al., eds. Advances and technical standards in neurosurgery. New York: Springler-Wien, 1985; Vol. 12.

30. Nieuwenhuys R, Voogd J, Van Hiujzen C. The human central nervous system. Berlin Heidelberg, New York: Springer-Verlag 1978.

31. Price JL, Russchen F, Amaral DG. The amygdaloid complex: In: Bjorklund A, Hokfelt T, Swanson LW, eds. Handbook of Chemical Neuroanatomy. Vol 5. Amsterdam: Elsevier, 1987; 279-388.

32. Swanson LW, Kohler C, Bjorklund A. The limbic region. In: Bjorklund A, Hokfelt T, Swanson LW, eds. The Septohippocampal system: Handbook of Chemical Neuroanatomy. Vol 5: Integrated Systems of the CNS, Part 1. Amsterdam: Elsevier 1987; 125-277.

33. Rosene DL, Van Hoesen GW. Hippocampal efferents reach widespread areas of cerebral cortex and amygdala in the rhesus monkey. Science 1977; Vol. 198.
34. Sheperd GM. The synaptic organization of the brain. Oxford University Press, 1975

35. Jackson JH, Colman WS. Case of epilepsy with tasty movements and "dreamy state" - very small patch of softening in the left uncinate gyrus. Brain 1988; 580-590.

36. Jasper $\mathrm{H}$. Electrical activity in the depth of the cortex as compared to that on the surface. Trans Am Neurol Assoc Chicago 1955; 21-22.

37. Jasper H, Pertuiset B, Flanigin H. EEG and cortical electrograms in patients with temporal lobe seizures. Arch Neurol Psychiatry 1951; 65: 272-290.

38. Jasper H, Rasmussen T. Studies of clinical and electrical responses to deep temporal stimulation in man with some considerations of functional anatomy. Adv Res Nerve Ment Dis, Proc, 1956.

39. Crandall PH, Walter RD, Rand RW. Clinical applications of studies on stereotactically implanted electrodes in temporal lobe epilepsy. J Neurosurg 1963; $21: 827-840$.

40. Halgren E, Walter RD, Cherlow DG, Crandall PH. Mental phenomena evoked by electrical stimulation of the human hippocampal formation and amygdala. Brain 1978; 101: 83-117.

41. Olivier A, Taylor L. Results of temporal lobectomy on intellectual function. XVth Epilepsy International Symposium (abst Washington, DC). September 1983; 151. 